Editorial

\title{
Closer to a polio-free Eastern Mediterranean Region
}

\author{
A. Alwan ${ }^{7}$ and C. Maher ${ }^{2}$
}

After a long hard struggle, the start of this decade saw the fight to eradicate polio from the Eastern Mediterranean Region appearing to bear fruit. In 2011 and 2012, only two countries in the Region were reporting wild poliovirus - Pakistan and Afghanistan, two of the last endemic countries in the world. By the end of 2012, when only 95 cases were reported in total from the Region, it seemed that finally stopping the transmission of poliovirus was just around the corner. The number of cases and countries were at the lowest-ever recorded levels (1).

However, progress was not as solid as it seemed, and a number of factors aligned that endangered the achievement of polio eradication. Constant conflict in Afghanistan and bans on immunization campaigns in some areas had led to the build-up of numbers of susceptible children. In Pakistan, even in 2011 and 2012 when environmental sampling designed to detect the overall presence of wild poliovirus in communities commenced, up to two-thirds of all the samples collected were positive. In late 2012, when attacks began on vaccinators, the virus was prevalent enough to take advantage of the disruption to the delivery of the programme that extended through 2013 and into 2014. As a result, by the end of 2014 Pakistan had recorded the highest annual number of polio cases for 10 years.

Additionally, conflicts and insecurity in polio-free countries in the Region had opened up gaps in immunization that wild poliovirus was able to exploit. In April 2013, virus imported from Nigeria caused the first case of an outbreak in Somalia that was to spread into neighboring countries and take 18 months to bring under control. Similarly in October 2013, the first cases were detected in Syria after the importation of wild poliovirus originating in Pakistan. This outbreak also spread into neighbouring countries, in this case Iraq, where the final case was not recorded until April 2014. The World Health Organization (WHO) declared in 2014 the international spread of wild poliovirus as a Public Health Emergency of International Concern (2). At that time many saw eradication as far away as ever.

But this impression was also incorrect. Despite conflict, insecurity and massive population displacement, coordinated multi-country outbreak responses involving the multiple immunization of more than 27 million children in the Middle East and millions more in the Horn of Africa brought a definitive stop to both outbreaks. WHO, the United Nations Children's Fund (UNICEF), and partners deployed strong surge teams to support responses even in conflict affected and security compromised areas. By November 2015 the evidence was clear enough for international review teams to declare both outbreaks closed. In September 2015, the Polio Oversight Board of the Global Polio Eradication Initiative reviewed progress and concluded that wild poliovirus transmission is more likely to be interrupted in 2016 than in 2015 (3). The response in the Middle East, despite the tremendously difficult situation presented by the conflicts in Syria and Iraq, succeeded in stopping the outbreak within 6 months of detection of the first case, and is widely regarded as a model response $(4,5)$. According to the 2015 Annual Report of the Polio Global Eradication Initiative, the world has never been closer to being polio-free (6).

In Pakistan and Afghanistan, aggressive new National Emergency Action Plans for polio eradication $(7,8)$, coordinated by national Emergency Operations Centres (EOCs) that bring together government and partners under the one roof, have opened the way to major programme improvements. Coupled with a massive surge in partner agency technical support - WHO alone has more than doubled the size of the teams working on polio in the two countries since the start of 2014, and now has nearly 2500 technical and operational experts in the field - these improvements have had a significant operational impact. At the time of writing, only 30 cases of polio have been recorded by Pakistan (18 cases) and Afghanistan (12 cases) combined so far in 2016 - a far cry from the 334 cases recorded by these countries in 2014 (9). Similarly, in 2016 only about one in 10 environmental samples in Pakistan has been positive for wild poliovirus, compared to one in every two in 2014.

The evidence now points to a wonderful opportunity to finally stop the transmission of wild poliovirus in the Eastern Mediterranean Region, and the coming months of the low transmission season offer our best hope ever. This must be the time when everyone, governments, civil society, and partners alike, redouble efforts to implement the strategies we know now to be effective in stopping polio. We have to seize this chance, and fulfill our promise to the children of our Region, and to the children of the world, to become polio-free, forever. 


\section{References}

1. WHO Executive Board. Poliomyelitis: intensification of the global eradication initiative. (EB132/17). Geneva: World Health Organization; 2012 (http://apps.who.int/gb/ebwha/pdf_ files/EB132/B132_17-en.pdf).

2. WHO statement on the meeting of the International Health Regulations Emergency Committee concerning the international spread of wild poliovirus. May 5, 2014. Geneva: World Health Organization; 2014 (http://www.who.int/mediacentre/news/statements/2014/polio-20140505/en).

3. Sixty-ninth World Health Assembly. Poliomyelitis. (A69/25). Geneva: World Health Organization; 2016 (http://apps.who. int/gb/ebwha/pdf_files/WHA69/A69_25-en.pdf).

4. Polio Global Eradication Initiative. Major multi-country epidemic prevented in the Middle East. Geneva: World Health Organization; 2015 (http://polioeradication.org/news-post/ major-multi-country-epidemic-prevented-in-the-middleeast)

5. Independent Monitoring Board of the Global Polio Eradication Initiative. The rocky road to zero - eleventh report May
2015. Polio Global Eradication Initiative. Geneva: World Health Organization; 2016 (http://polioeradication.org/wpcontent/uploads/2016/07/02E.pdf).

6. Global Polio Eradication Initiative. Annual Report 2015 - Eradication within reach. Geneva: World Health Organization; 2016 (http://polioeradication.org/wp-content/uploads/2016/10/ AR2015.pdf).

7. National Emergency Action Plan for Polio Eradication - Islamic Republic of Afghanistan 2016-2017 (http://polioeradication. org/wp-content/uploads/2016/10/NEAP2016-2017_Afghanistan-1.pdf).

8. National Emergency Action Plan for Polio Eradication - Islamic Republic of Pakistan 2015-2016 (http://polioeradication.org/ wp-content/uploads/2016/07/5.2_14IMB.pdf).

9. WHO Executive Board. Poliomyelitis. (EB136/21). Geneva: World Health Organization; 2015. (http://apps.who.int/gb/ ebwha/pdf_files/EB136/B136_21-en.pdf). 